\title{
An Actionable Orchestration Dashboard to Enhance Collaboration in the Classroom
}

\author{
Ishari Amarasinghe, Davinia Hernández-Leo, Konstantinos Michos, and Milica Vujovic
}

\begin{abstract}
The orchestration of collaborative learning activities in technology-enhanced classrooms has become a non-trivial endeavour for educators. Depending on the behaviours and needs of students that emerge in real educational situations, educators may need to orchestrate activity adaptations on the fly. These adaptations may range from the provision of additional scaffolding by the educator (e.g. the educator's participation in a group discussion) to a change in the planned pedagogical scenario (e.g. the duration). This study aims to contribute to the orchestration of technology-mediated collaborative learning sessions in a classroom context. We present the design, implementation, and evaluation of a teacher-facing dashboard that supports teachers in orchestrating scripted collaboration. Evaluation studies were conducted in $\mathbf{1 6}$ classroom sessions. The findings indicate that teachers found the information on the dashboard to be actionable and help facilitate just in time support to student groups.
\end{abstract}

Index Terms-Collaborative learning, scripts, learning analytics, orchestration, dashboards, learning technologies.

\section{INTRODUCTION}

$\mathrm{T}$ HE benefits of implementing computer-supported collaborative learning (CSCL) activities in technologyenhanced learning spaces are well-known [1]. Along with the integration of technological tools that aim to enhance learning in collaborative learning settings in the classroom, recently, researchers have become more interested in how to support educators who guide collaboration in these spaces, as the benefits of collaboration largely depend on how interactions occur among students [2]. On the other hand, in the context of collaborative learning, carefully designed collaboration scripts facilitate structuring of the flow of collaboration while triggering beneficial social and cognitive interactions that create positive effects on learning [1]. Different techniques (e.g. defining the activity sequence or role allocation) are used for

Manuscript received ; revised September 18, 2019, June 9, 2020, and September 22, 2020; accepted . Date of publication ; date of current version September 22, 2020. This work has been partially funded by "la Caixa Foundation" (CoT project, 100010434) and the National Research Agency of the Spanish Ministry of Science, Innovations and Universities MDM-20150502, TIN2014-53199-C3-3-R, TIN2017-85179-C3-3-R. (Corresponding author: Ishari Amarasinghe.)

The authors are with the Universitat Pompeu Fabra, Barcelona, 08018, Spain (email: ishari.amarasinghe@upf.edu; davinia.hernandez-leo@upf.edu; kostas.michos@upf.edu; milica.vujovic@upf.edu).

Digital Object Identifier scripts in order to increase the probability of productive student-student and student-teacher learning interactions, which would otherwise occur rarely or not at all in spontaneous collaborations [1], [3].

In the context of CSCL, collaborative learning flow patterns (CLFPs) formulate the essence of the script structures that have been proven to be effective in multiple educational situations [4]. Some well-known CLFPs include Jigsaw and Pyramid. The Pyramid CLFP provides an activity flow in which learners start to solve a task individually. Learners then formulate small groups to share their solutions and discuss, to agree on a common solution, forming increasingly larger groups as the flow advances. This CLFP provides opportunities for all learners to express and discuss their solutions and to learn and reflect on others' ideas. However, achieving success in the Pyramid script depends on the continuous and active participation of students throughout the consecutive phases of the script. A lack of continuous activity participation of students negatively affects the meaningful progression of the activity flow (e.g. inactive groups delaying the progress of the active groups in reaching a consensus) resulting in unfruitful learning experiences [5].

In the domain of CSCL, how an active and an energetic teacher manages integrated learning scenarios in real-time in a highly constrained environment is referred to as orchestration of the collaborative learning activity [6]. Even though scripts maintain the pedagogical structure of collaborative learning activities, teachers are required to play an active role in monitoring and adapting the scripts when necessary. For instance, when a collaborative learning script, such as the Pyramid CLFP, is deployed, it adds a level of complexity in the orchestration related to changes in group formation along a sequence of activities, with constraints related to expected group sizes and synchronicity among groups to enable a flow progression compliant with the pattern so as not to destroy its potential pedagogical benefits. Orchestrating such activities can prove challenging or, often, infeasible without proper technological tools, support, and infrastructure. To this end, we have studied the challenges teachers may face when orchestrating scripted collaborative learning sessions in the classroom and how a technological tool, such as a teacherfacing dashboard, could support teachers in orchestrating collaboration in real time. The proposed dashboard is novel as it provides actionable analytics on how collaboration evolves in 
real time.

Actionable analytics can be understood as analytics concerned with the potential for practical action rather than theoretical description or mere reporting [7]. The information presented by learning analytics (LA) tools can provide insights and create possibilities for guided actions to promote better end results. However, simply presenting information does not always help teachers to obtain a deeper understanding of the learning situation and subsequently make pedagogical decisions [8]. Rather, careful consideration must be paid to which type of information to present [9], when specifically aiming to influence future teacher decisions.

In our study, first, we conducted an analysis to better understand which information should be presented on the dashboard, and then we focused on which types of controls are required to be embedded in the dashboard to help teachers take necessary pedagogical actions. The context of our analysis is scripted collaboration in the classroom. In this context, information deemed 'actionable', alerts teachers to critical occurrences, such as low participation in a group, that requires intervention, such as diagnosis of the reason for lack of participation and provision of instructions to overcome the problem. An LA dashboard can visualise such critical moments and provide means for intervention, such as posting messages to groups. Another common problem is that students run out of time for collaboration. Information about how many groups have completed collaboration and how many groups have yet to finish the activity can create awareness and a call for action, such as increasing the time for the activity. In this way, the teacher can reconfigure the script parameters on the fly. By raising awareness of the problems and eventualities associated with collaboration, teachers can translate their knowledge into action. LA tools can be positioned as mediators that provide information about the problems and guidance for actions.

We followed the iterative workflow suggested in the Learning Awareness Tools - User eXperience (LATUX) workflow to design, deploy, and validate our proposed LA dashboard [10]. The LATUX workflow was applied since it was specifically proposed for projects that aim to design and deploy tools for improving instructors' awareness of students' learning activities in the classroom [10]. The LATUX workflow constitutes five steps: problem definition, low-fidelity prototyping, higher-fidelity prototyping, pilot studies, and classroom use or validation in the wild. We now describe how these workflow phases were applied within the present study.

The following two research questions are addressed:

RQ1: How did teachers use the dashboard to orchestrate collaboration?

RQ2: Do teachers' orchestration actions affect students' participation in activities?

The research aim of this paper is threefold. First, we investigate the challenges teachers face when orchestrating classroom collaboration with a focus on pyramid pattern-based scripted scenarios. Second, we explore the design details of an LA dashboard that implements different controls to support teachers in managing the collaborative learning sessions flexibly during the run-time of the activity in different ways.
Third, we present an evaluation of the proposed LA dashboard, showing how teachers responded to the analytics that made information on the dashboard actionable and how teachers' pedagogical actions affected students' participation in the activity along with the lessons learned and guidelines for future research.

The rest of the paper is organised as follows. Section II presents related work describing how LA has been used to support teachers when orchestrating collaboration in previous studies. Section III presents the difficulties associated with orchestrating collaboration in classroom sessions. Section IV explains the design and implementation of the proposed LA dashboard in detail. Section V describes the methods. Section VI presents the study results. Section VII discusses the results, and Section VIII presents the study's limitations. Section IX concludes the paper and provides future research directions.

\section{RELATED WORK}

LA is defined as the "measurement, collection, analysis, and reporting of data about learners and their contexts, for the purposes of understanding and optimizing learning and the environment in which it occurs" [11]. Recently, LA has gained a lot of attention as it offers the opportunity to better understand learning processes and gain insights into how to improve teaching practices [12], [13]. Several studies have proposed different LA interventions to support teachers as described below.

Alavi et al. [14] presented a tool called Lantern to support tutor-team interactions in collaborative problem-solving sessions in the classroom. The tool aimed to provide information on the work status of each group (by changing the colour, intensity, blinking, and frequency of blinking of the lantern) to the tutor, who could decide in real time which group to focus on when multiple groups requested help at the same time.

Mercier et al. [15] emphasised the importance of providing control tools for teachers to adapt learning activities and proposed a tool to monitor performance and manage groups engaged in solving mathematical problems in a multi-touch classroom setting. The case studies show that the tools enabled teachers to alter the difficulty of the learning task based on the student's needs.

Slotta et al. [16] developed an instructor's tablet that informed students' activity participation in a smart classroom setting. The tool enabled teachers to change activities according to groups' performance.

Schwarz et al. [17] focused on providing information about critical moments to teachers while groups worked in parallel. The authors stressed the importance of providing information about critical moments to educators in real time in order to improve orchestration and facilitate interventions, such as asking an idle group whether they are having problems that may lead to the emergence of learning in classroom settings.

Several researchers have also explored how LA dashboards can support teachers and learners [18]. LA dashboards have been defined as "single displays that aggregate different indicators about learner(s), learning process(es), and/or 
learning context(s) into one or multiple visualisations" [19]. Research on LA dashboards aims to identify which data are meaningful to different stakeholders and how data can be presented to support the sense-making processes of the target stakeholder group [19].

Martinez-Maldonado et al. [20] developed the MTDashboard, which provides indicators of small group collaboration and controls components intended to support teachers when orchestrating activities. Martinez-Maldonado et al. [21] also presented another LA dashboard tool that provides different visualisations (e.g. radars of touch and verbal participation) to provide an overview of the collaborative activity of learners in a tabletop environment.

Rojas et al. [22] proposed a dashboard that kept track of students' help requests during a laboratory session. The dashboard provided visualisations to indicate students' progress, help requests, and time-related aspects of tutoring.

Do-Lenh et al. [23] proposed TinkerLamp 2.0, an orchestration system that provided teachers with the authority to control the progression of the activity. A dashboard (i.e. TinkerBoard) was added to the system to visualise groups' progress, which allowed teachers to remain aware of group activities, mediate help requests, and determine when to intervene.

Some of the common controlling functions built into the aforementioned tools include: 1) controls to start and finish the activity; 2) ways to send messages to groups, such as reminders of the time left for the activity; 3) blocking and unblocking controls for the teacher to get students' attention when needed; 4) controls to move to the next stage of the task; 5) controls to change the difficulty of the task; and 6) controls to project students' screens on wall displays/interactive whiteboards. In addition, the information presented by the tools aims to raise teachers' awareness of group processes and help requests, and alerts are generated to indicate idleness and off-topic discourse within groups. By providing a quick overview of how collaboration evolves using aggregated information, LA can support teachers in overcoming the limitations of working memory and building awareness, hence facilitating productive intervention for groups that require immediate attention [24].

Despite the aforementioned benefits, recent systematic literature reviews published on LA dashboards have highlighted that existing research is rarely grounded in learning theories [18], [25] and that rigorous needs assessments are vital to understand end users' needs and determine which problems must be addressed by the proposed LA solution [26]. As emphasised in [25], existing research on LA dashboards has had significant limitations in terms of how evaluations are conducted. Very few dashboard evaluations have been conducted in authentic settings, as many of the proposals have been exploratory and built as proofs of concept [19]. Moreover, how teachers make sense of the data presented using LA dashboards and subsequently make decisions about relevant pedagogical actions in authentic contexts is not yet fully understood [27]. Schwendimann et al. [19] reported that although research on LA dashboards is growing in popularity, there is a lack of comparative studies on different dashboards, and the extent to which study results can be generalised to different learning contexts must be investigated. Finally, the impact of these technologies on target stakeholders has rarely been reported. For example, few studies have mentioned whether the dashboard improved the awareness of teachers and students, although the adoption and impact of LA dashboards are probably the most important aspects of research on this topic [19]. In this study, we propose a dashboard that aims to support teachers orchestrating scripted collaborative learning sessions. Using co-design techniques such as guiding questions, low fidelity prototyping, and pilot studies we attempted to involve teachers in the design process. Following the guidelines of the LATUX workflow, we report in detail the needs assessment, design process, and results of the evaluations conducted in authentic settings, highlighting the impact of the proposed technology on both teachers and students.

\section{DifFiculties Associated With ORChestrating COLLABORATION}

During the first phase of the LATUX workflow (i.e. the problem identification phase), we studied the problems that teachers face when conducting collaborative learning sessions. We conducted four workshops at two secondary and vocational education schools in Spain (two workshops at each school) that aimed to identify common problems faced by teachers and to introduce different tools that could be used to facilitate collaborative learning sessions. In total, 15 teachers (with 3-26 years of teaching experience) who frequently conduct collaborative learning activities in their classrooms participated in the workshops. In the first workshop, a brainstorming activity was conducted to capture the difficulties teachers face when conducting collaborative learning activities in classrooms. Teachers' verbal responses were recorded and subsequently analysed using affinity diagrams. An iterative approach was applied to group the main themes. The results of the analysis revealed that the difficulties could be categorised into two themes. The first theme describes the difficulties associated with planning collaborative learning tasks, such as those related to the formulation of collaborative learning tasks or to the design of parameter configurations, and formation of groups. The second theme reflected the importance of maintaining students' participation during the activity.

During the second workshop, teachers were asked how technology could help to solve the challenges identified in the first workshop. The responses revealed that teachers prefer tools that allow them to flexibly control activities as they are occurring, as it is difficult to configure learning design parameters, such as duration, at the initial stage of activity design. Also, they preferred information that was visualised in an actionable format. For example, upon detecting groups with low participation, teachers wanted to perform timely interventions, such as sending text messages to encourage participation in the activity.

Four university teachers (two male and two female) from Spain with 1-5 years of teaching experience were interviewed in a face-to-face working session in order to further understand the difficulties associated with conducting scripted 
collaborative learning activities in classrooms. We considered a setting in which collaboration was scripted according to the Pyramid CLFP and deployed using PyramidApp (details about which are provided below) [28]. All four teachers had prior experience with using PyramidApp [28]. We discussed with the four teachers the possible problems that may occur during Pyramid activities and asked them to write down how they would attempt to solve those problems and improve orchestration (see Table I).

PyramidApp is a web-based tool that enables teachers to design and deploy Pyramid pattern-based collaborative learning activities [28]. In a classroom session, the tool helps allocate students into multiple pyramids (groups) and reach consensus for a given task following a pyramid structure. When authoring Pyramid activities, teachers must configure the following design parameters: 1) the number of participants per pyramid;

TABLE I

Responses COlLected From Teachers on How to Handle Problems DURING PYRAMID-BASED COLLABORATIVE LEARNING SESSIONS

\begin{tabular}{|c|c|}
\hline Problem & Response $^{\text {a }}$ \\
\hline Students cannot log in & $\begin{array}{l}\text { A: Find the best way to log in } \\
\text { B: Ask to join the student next to them } \\
\text { C: Use the projector to show how to log in } \\
\text { D: Pause the system and ask to join the } \\
\text { student next to them }\end{array}$ \\
\hline $\begin{array}{l}\text { Some students skip the } \\
\text { initial answer } \\
\text { submission stage }\end{array}$ & $\begin{array}{l}\text { A: Advise students to be more rigorous in } \\
\text { the following rounds } \\
\text { B: Enter the chat and initiate discussion } \\
\text { C: Use the chat to encourage them to use } \\
\text { the system correctly and provide more time } \\
\text { if necessary } \\
\text { D: Pause the system and ask about the } \\
\text { reason }\end{array}$ \\
\hline $\begin{array}{l}\text { Students' answers are } \\
\text { not up to the teachers' } \\
\text { expectations }\end{array}$ & $\begin{array}{l}\text { A: Tell students their work is taking the } \\
\text { wrong direction } \\
\text { B: Talk to students and restart the activity } \\
\text { C: Send a message in the chat, suggesting } \\
\text { some keywords } \\
\text { D: Pause the system and ask the reason } \\
\text { A: Ask students to respect time }\end{array}$ \\
\hline $\begin{array}{l}\text { Students do not submit } \\
\text { answers on time }\end{array}$ & $\begin{array}{l}\text { B: Extend the time of the activity } \\
\text { C: Increase the original amount of time } \\
\text { given } \\
\text { D: Pause the system and ask the reason }\end{array}$ \\
\hline $\begin{array}{l}\text { Students drop out due } \\
\text { to connectivity } \\
\text { problems }\end{array}$ & $\begin{array}{l}\text { A: Try to finish the activity orally } \\
\text { B: Go back to regular answers and } \\
\text { questions } \\
\text { C: Pause the system and ask the reason } \\
\text { D: Pause the system and ask the reason }\end{array}$ \\
\hline $\begin{array}{l}\text { Low on-task } \\
\text { participation (voting } \\
\text { and discussion) }\end{array}$ & $\begin{array}{l}\text { A: Encourage students to participate } \\
\text { B: Pause the activity and ask what is } \\
\text { happening, pose some questions in students' } \\
\text { discussions } \\
\text { C: Pause the system and send a message } \\
\text { clarifying how the system works } \\
\text { D: Pause the system and ask the reason }\end{array}$ \\
\hline $\begin{array}{l}\text { Groups take more time } \\
\text { to finish than expected }\end{array}$ & $\begin{array}{l}\text { A: Rescale activities for the next session } \\
\text { B: Consider small groups for the next time } \\
\text { C: Increase the time } \\
\text { D: Increase the time }\end{array}$ \\
\hline $\begin{array}{l}\text { Some groups finish } \\
\text { earlier than expected } \\
\text { and are waiting for } \\
\text { other groups to finish }\end{array}$ & $\begin{array}{l}\text { A: Hurry other groups to finish } \\
\text { B: Limit time for other groups } \\
\text { C: Send a message to encourage } \\
\text { participation } \\
\text { D: Encourage students to finish the activity }\end{array}$ \\
\hline
\end{tabular}

${ }^{a} \mathrm{~A}, \mathrm{~B}, \mathrm{C}, \mathrm{D}$ denote each teacher's response

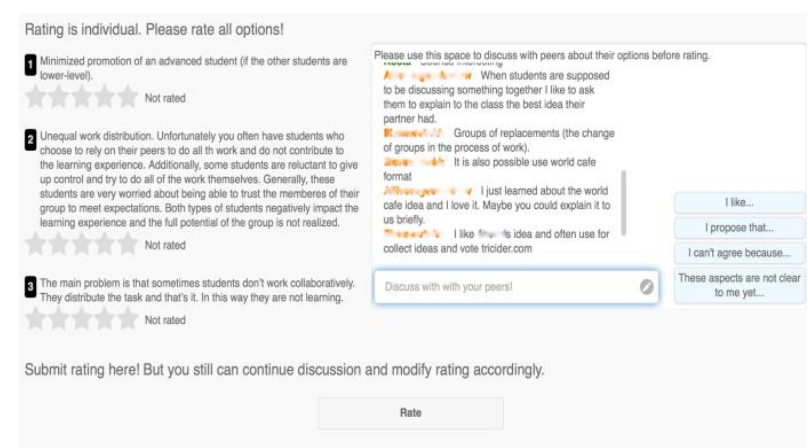

Fig. 1. User interface of the PyramidApp tool showing the answers to be voted upon (left) and discussion space (right).

2) the number of voting levels per pyramid (the tool provides a voting mechanism to achieve agreement on common solutions within collaborative groups); 3) group size at the first voting level of the pyramid (based on this input, the tool calculates the size of the groups for the next pyramid level); and 4) duration of the initial stage of answer submission and subsequent voting stages. Once the activity is designed, the teacher can generate a public link that can be shared with students to allow them to log into the tool. Once logged in, students are required to individually write answers for the given task. Then, students are automatically randomly allocated into small groups. Within each small group, students see the individual answers submitted by their group members, and students are expected to discuss (using the discussion board built into the tool), and vote on the answers (see Fig. 1). At the end of this phase, small groups are merged to form larger groups. Within the larger groups, students can see which answers were upvoted during the previous phase and then further discuss and vote on the answers. At the end of the activity, the winning answers from different pyramids are presented.

Teachers' activity design configurations and students' activity enactment data are logged in the PyramidApp database. Log data captured in the PyramidApp database was used to visualize relevant information on the proposed dashboard.

Selected feedback from the four teachers regarding how they would use PyramidApp and, more specifically, how they would handle issues is documented in Table I. As revealed by the teachers' responses, teachers attempt to solve problems either verbally (by providing explanations) or via technological means to target specific problematic groups. For example, teachers may pause the activity to get the class's attention when providing instructions on how to overcome common problems. In some instances, teachers may also wish to modify initial design parameters, such as duration, to adapt the script to the requirements of the current classroom situation.

\section{AN ACTIONABLE ORCHESTRATION DASHBOARD: CONTROLS AND IMPLEMENTATION IN THE CASE OF PYRAMIDAPP}

Following the LATUX workflow, the next step involved building low-fidelity (paper) prototypes to obtain a representation of the intended design and enable a high-fidelity 
prototype to be developed subsequently. We designed four paper prototypes that depicted students' participation in a Pyramid activity. The design of these prototypes was informed through literature review [20], [21], [23] and the teachers' responses (Table I). We also followed the guidelines presented in the Chao software framework when presenting information on the dashboard [29]. As indicated in the Chao framework, we split data across two dimensions: progress and product. Progress-related data visualised the student's pace at a class level, and product-related data provided details about the student's submissions, such as answers, notes, and discussions [29].

The paper prototypes were tested following the LATUX workflow guidelines presented in [10]. We first evaluated the usability of the provided visualisations and then evaluated whether the visualisations provided insights regarding differences in the participation of the groups. Teachers provided feedback and suggested improvements to the paper prototypes. The feedback collected from the teachers led to the definition of three different types of controls-timing, flow, and participation - to handle problems that may occur during the activity. Timing and flow controls enable adaptation of the design parameters of the activity on the fly. For instance, timing controls enable teachers to adjust the time allocated to different phases of the script in real time. Flow controls (i.e. pause, resume, and end) enable teachers to get the class's attention when needed by pausing the activity or to permanently exit the collaborative learning activity when, for example, the activity takes longer than expected. Participation controls detect low participation of groups and notify teachers with warnings to facilitate timely interventions.

We held two focus group sessions with the four teachers and undertook a small pilot study in a lab session with one teacher to obtain further feedback regarding the features and functionalities of the proposed dashboard prototypes. Teachers' feedback was taken into account to enhance the visualisations and determine the functionalities of the controls introduced in the dashboard. The following paragraphs describe the final design of the dashboard that was used in real-world classroombased trials.

Fig. 2 shows an excerpt of the upper part of the Submission Related Information tab with the following information: 1) the total number of students currently logged into PyramidApp; 2) the total number of individual answers submitted at a given time; 3 ) the number of pyramids created; and 4) the number of winning answers (indicating that certain pyramids have finished the collaborative learning activity). The lower part of the user interface was divided into three sections to distinguish between the artefacts produced or agreed upon at different phases of the Pyramid script: individual answers, highly rated answers (in intermediate phases), and winning answers (at the end of the

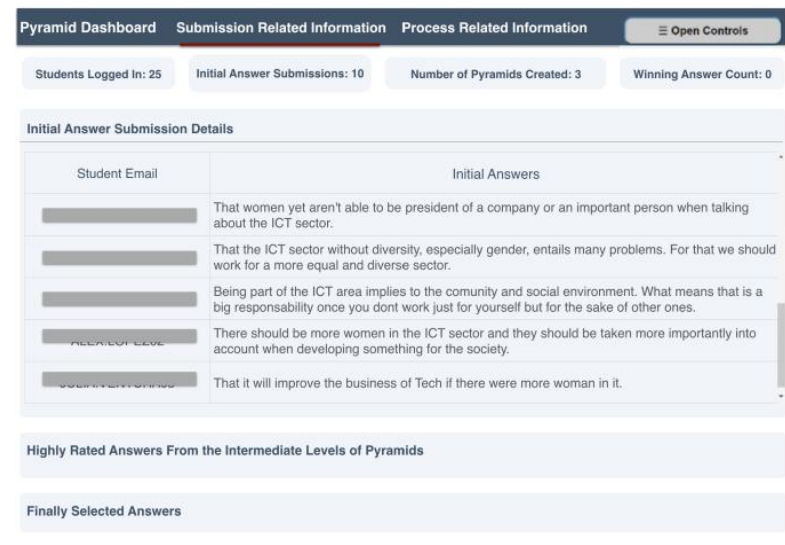

Fig. 2. Information presented in the Submission Related Information tab of the dashboard.

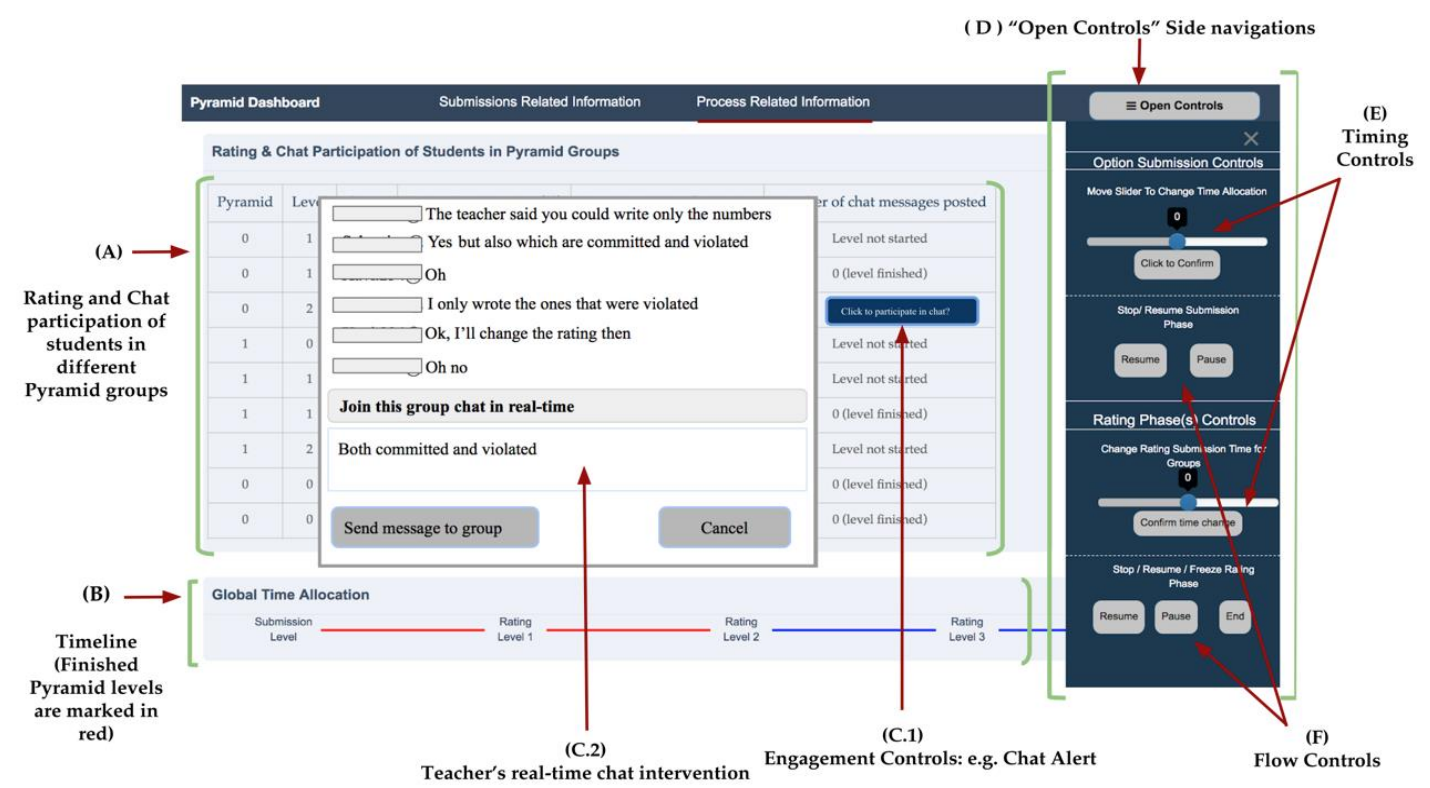

Fig. 3. Information presented in the Process Related Information tab and dashboard controls. 
activity)

As shown in Fig. 3, the information presented under the Process Related Information tab was divided into two sections. The upper part of the user interface visualised the voting (the number of students who participated in voting within each group, shown as a percentage) and discussion participation (the number of chat messages posted in each group) of students at different phases of the Pyramid script using a tabular design (see Fig. 3 (A)). A timeline was included in the lower part of the user interface to reveal the script progression in real time (see Fig. 3 (B)). The labels of the timeline were generated automatically. For instance, three phases of the Pyramid design were visualised in the timeline as submission level, rating level 1 , and rating level 2 . The length of the timeline was adjusted during the run-time of the activity and reflected the time allocated for each phase.

Participation controls were built into the Process Related Information tab. As described earlier, these controls kept track of students' voting and participation in discussions. The focus group teachers stated that a warning is wanted when there is a lack of participation in voting or discussions. It was decided that a voting warning would be generated when the majority (more than $50 \%$ ) of a given group did not participate in voting and a discussion warning would be generated when fewer than two messages were posted by a group. When a warning should be displayed on the dashboard was discussed with the teachers, and it was agreed that warnings should appear only after 50\% of the time allocated to a certain phase expired. These design decisions aimed to minimise the number of warnings simultaneously appearing on the dashboard and to provide adequate time for the students to collaborate. Fig. 4 shows an example of a voting warning. Touching a voting warning on the dashboard opened a confirmation dialog that included the following options: 1) select one answer; 2) promote a random answer; and 3) promote all answers for further discussion in the next Pyramid level. The teacher could choose their voting decision and confirm the action or dismiss the warning.

Fig. 5 shows an example of a discussion warning. Touching a discussion warning opens a dialog box that shows the messages posted on the group discussion board in real time and allows teachers to post messages to groups. Teachers were also able to send messages to groups at any time, even without receiving a discussion warning (see Fig. 3 (C.2)).

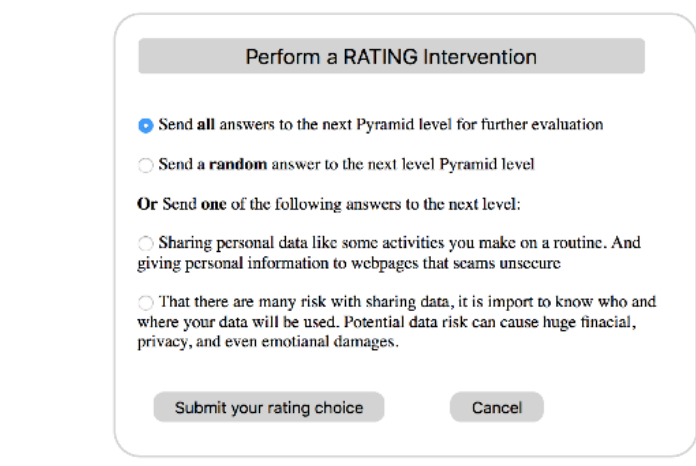

Fig. 4. An example of a voting warning.

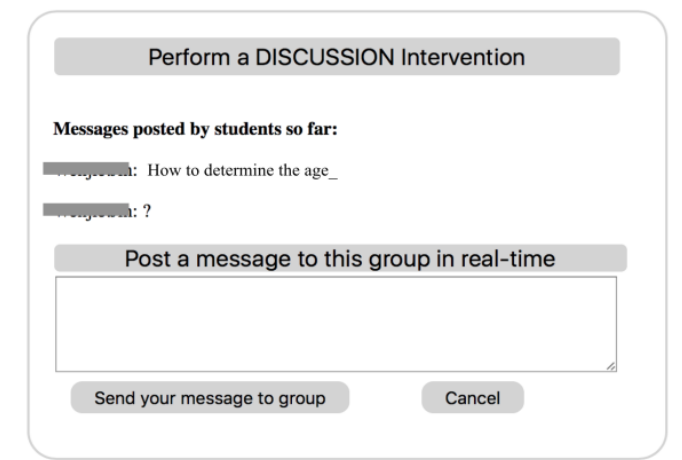

Fig. 5. An example of a discussion warning.

A panel on the right, which we refer to as the Open Controls panel (see Fig. 3 (D)), was also included in the dashboard. It included timing and flow controls, and it is divided into two sections-Option Submission Controls and Rating Phase(s) Controls - to represent the applicability of the controls to different levels of the Pyramid script. Within this panel, an interactive slider was included as a timing control (see Fig. 3 (E)). The slider enables the teacher to re-configure the time allocated to different Pyramid levels as required. Its default position was 0 , and based on the feedback received from the teachers, the moving range of the slider was set between -1 and +1 minute. Moving the slider right increased the time by 1 minute, and moving the slider left decreased the time by 1 minute. The change of time was limited to a 1-minute difference because the teachers mentioned that they do not wish to drastically change the time allocated to the activity. Increasing the activity time was required in situations where students or groups needed more time to finish certain phases, while decreasing time was required when all groups finished the activity earlier than anticipated. The panel also included other flow controls, such as pause, resume, and end (see Fig. 3 (F)), which are described earlier.

\section{METHOD}

\section{A. Participants}

Following the LATUX workflow, we conducted validation studies in a real setting. Four teachers (two males and two females who did not take part in any of the previous stages of the workflow) from a Spanish university participated in 16 authentic class sessions. Teachers were recruited for the study given they were instructing a subject with a sufficient number of students and had available sessions for experimentation. The teachers were used to incorporating collaborative learning activities within their courses, and they were interested in using technological tools in the classroom. All four teachers had prior experience with PyramidApp. However, none of them had experience with using dashboard applications to orchestrate collaboration. First-year undergraduate students from the classes took part in the study with informed consent. Ethics approval for the study was obtained from the Institutional Committee for Ethical Review of Projects (CIREP) from the Universitat Pompeu Fabra (CIREP approval number: 129). 


\section{B. Procedure and Data Collection}

First, the experiments without the dashboard were conducted, and then those with the dashboard were conducted. In the experimental condition, teachers monitored and orchestrated group activities using the dashboard, and in the control condition, the dashboard was not available. Training was provided to the teachers to ensure they were familiar with the features of the dashboard before the experiments. An overview of the sessions and the data collection instruments used to address the research questions are presented in Table II. The design configurations of the Pyramid activities in each session varied based on the teachers' requirements for collaborative learning activities in the classroom sessions. In all sessions, teachers proposed open-ended knowledge sharing tasks for students.
Students' collaboration in both conditions and teachers' dashboard actions in the experimental condition were automatically logged. In the experimental condition, teachers' dashboard actions were also recorded using screen-captured data (audio and video) from the dashboard tablet. Moreover, a researcher performed classroom observations during each session. Every time the teacher consulted the dashboard; made announcements to the class; or engaged in discussions with students, the researcher wrote down the time and detail of the action. Two datasets were created to denote teachers' actions during the experimental and control conditions: 1) screencaptured data from the tablet, log data and observation notes (along with timestamps) to reflect teachers' actions in the experimental condition; and 2) observation notes to reflect teachers' actions in the control condition.

TABLE II

PYRAMID ACTIVITIES CONDUCTED In EXPERIMENTAL AND CONTROL CONDITIONS ALONG With THE ACTIVITY CONFIGURATIONS, DATA SOURCES USED to ANSWER RESEARCH QUESTIONS AND THE TYPE OF ANALYSIS PERFORMED

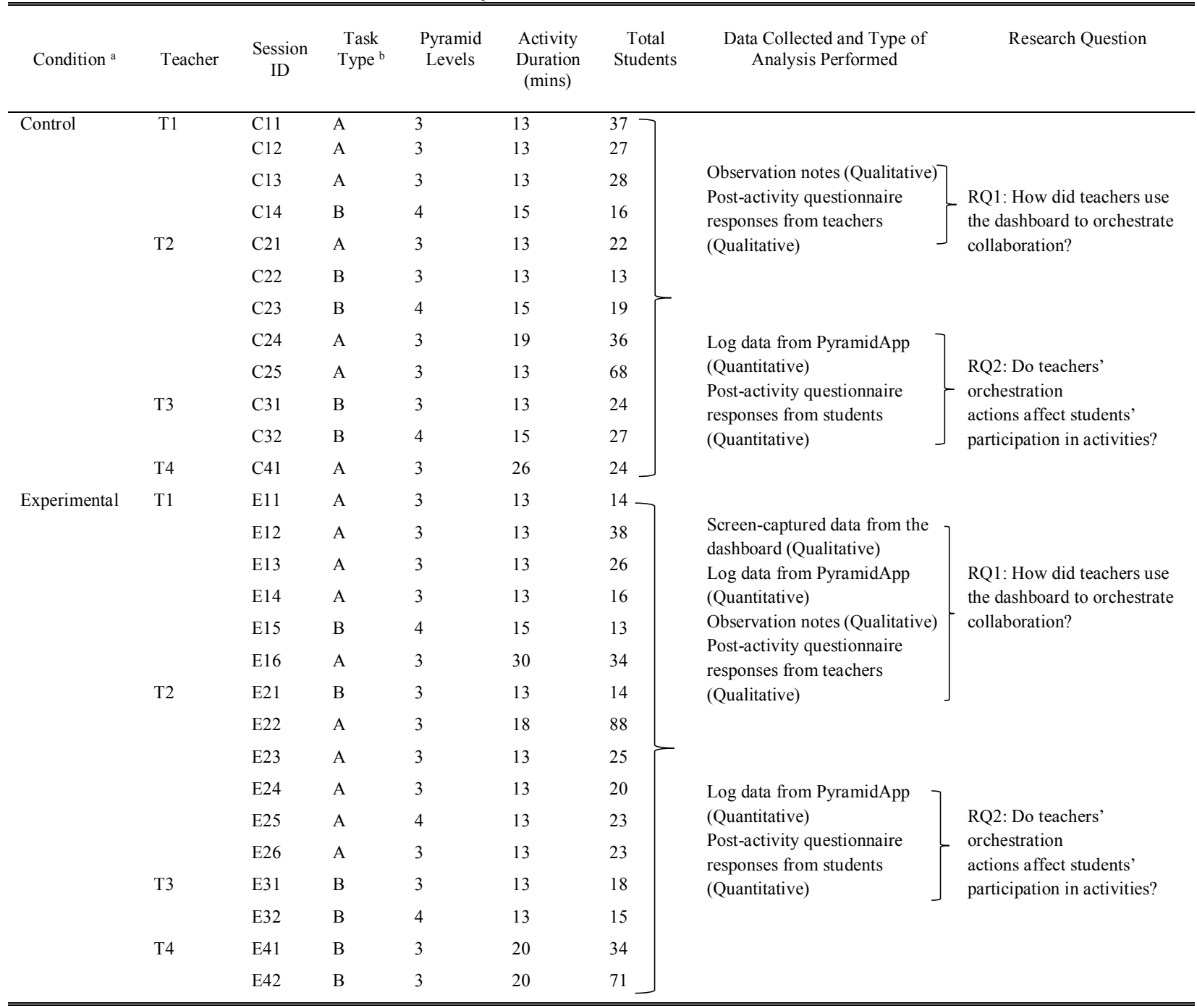

aThe control condition was run first by all four teachers then the experimental condition.

${ }^{\text {b} T a s k ~ A ~ r e f e r s ~ t o ~ c a s e ~ s t u d y ~ a n a l y s i s ~ a n d ~ T a s k ~ B ~ r e f e r s ~ t o ~ p r o b l e m ~ s o l v i n g ~ a c t i v i t i e s, ~ w h i c h ~ b o t h ~ r e q u e s t ~ f o r ~ c o l l a b o r a t i v e ~ n e g o t i a t i o n . ~}$ 
At the end, a post-activity questionnaire was used to collect teachers' perceptions of the activities and dashboard. A postactivity questionnaire with 2 qualitative questions were given to students. Students responded to the questions on a five-point Likert scale ( 1 = totally agree, $5=$ totally disagree): 1$)$ "I have learned a lot about the subjects discussed during the collaborative learning activity" (which reflected perceived learning); and 2) "rate your overall satisfaction with the collaborative learning experiences" (which reflected perceived satisfaction). A mixed-methods approach was used to contextualise and triangulate quantitative and qualitative data to produce results for the two conditions.

\section{Coding Teachers' Actions}

Wise and Jung [27] presented a model of instructors' analytics use (which is a two part structure of, sense-making and pedagogical response) to describe common activities in which instructors engage with when using analytics. We adopted the model to code actions observed in our study (see Table III).

As shown in Table III we utilised seven codes from the model to code teachers' actions in the experimental condition. For the control condition, three codes were used to code teachers' actions. Two authors of this paper coded the datasets. There was high agreement between the two coders (Cohen's Kappa $=0.95$, $\mathrm{p}<0.005$ ), and any disagreements were resolved by discussion.

\section{RESULTS}

\section{A. How Did Teachers Use the Dashboard to Orchestrate Collaboration?}

In the experimental condition, the four teachers read data (or checked information on the dashboard) an average of 13.5 times per session, with a standard deviation of 3.76 times. The frequency with which teachers read data from the dashboard ranged from 6 to 18 times per session, indicating variation. Teachers explained the patterns observed in the data to students an average of 2.94 times per session, with a standard deviation of 2.05 times. In terms of pedagogical responses, the most frequent action teachers took after consulting the dashboard was whole-class scaffolding (an average of 7.69 times per session, $\mathrm{SD}=4.9)$. In comparison, teachers performed less targeted scaffolding after consulting the dashboard (an average of 3.56 times per session, $\mathrm{SD}=3.4$ ). In the 16 sessions, actions to: revise course design; wait and see; and check impact were observed less often. Revision of course design was observed an average of 0.88 times $(\mathrm{SD}=0.62)$, waiting and seeing was observed an average of 1.88 times $(\mathrm{SD}=2.03)$, and checking impact was observed an average of 0.25 times $(\mathrm{SD}=0.77$ ).

Table IV provides details on teachers' reactions to dashboard warnings and the use of dashboard controls in the experimental condition. As shown in Table IV, teachers reacted to voting warnings in 6 of the 6 experimental sessions (that generated warnings), with teacher $\mathrm{T} 1$ reacting in four sessions and teachers $\mathrm{T} 2$ and $\mathrm{T} 3$ each reacting within a single session. Three teachers reacted to discussion warnings in 5 of the 8 experimental sessions (that generated warnings), with teacher $\mathrm{T} 1$ reacting in three sessions, and teachers $\mathrm{T} 3$ and $\mathrm{T} 4$ each reacting within a single session. The sixth column in Table IV indicates whether students replied to the messages posted by the teachers (yes/no). In total, students posted 56 messages in teacher T1's sessions and 3 messages in teacher T3's session, showing that teachers' intervention in chats in real time triggered discussions among students. However, no replies were received for the discussion interventions performed by teacher T4. To achieve further understanding, we analysed the types of messages posted by the three teachers. The analysis revealed that discussions were triggered only when $\mathrm{T} 1$ and $\mathrm{T} 3$ asked students to discuss their voting decisions. T4 posted only greeting messages (e.g. Hello) to groups, which did not trigger discussions among students.

Regarding the flow controls, log data indicated that 12 of the 16 sessions (i.e. E12, E13, E14, E15, E16, E22, E24, E25, E26, $\mathrm{E} 32, \mathrm{E} 41$, and $\mathrm{E} 42$ ) were terminated by four teachers using the end control before the time limit was reached. According to the observation notes, during those sessions, teachers presented the selected answers to the class when the majority of the groups had not reached the final voting level (e.g. "We have one winning answer. I'll wait 1 minute more, and I'll discuss some other chosen ones.") However, none of the teachers used the pause and resume controls. Timing controls were used only by

TABLE III

CODING SCHEME USED TO DESCRIBE TEACHERS' ACTIONS

\begin{tabular}{|c|c|c|}
\hline Category & Code $^{\text {a }}$ & Explanation \\
\hline \multirow[t]{2}{*}{ Sense-making } & Read data & Teacher is reading the data presented on the dashboard. \\
\hline & Explain pattern & $\begin{array}{l}\text { Teacher explains the observed collaboration patterns. In the experimental condition, dashboard data was used to explain } \\
\text { patterns. In the control condition, the teacher used perceptions and observations of individual students' devices to } \\
\text { explain patterns (e.g. "Some groups have already finished the voting, but some of you still haven't yet.") }\end{array}$ \\
\hline \multirow[t]{5}{*}{$\begin{array}{l}\text { Pedagogical } \\
\text { Responses }\end{array}$} & $\begin{array}{l}\text { Whole-class } \\
\text { scaffolding }\end{array}$ & $\begin{array}{l}\text { Teacher provides support at the class level, describing the PyramidApp mechanism, task, script progression, } \\
\text { participation, and quality of artefacts (e.g. "Click submit when you finish.") }\end{array}$ \\
\hline & $\begin{array}{l}\text { Targeted } \\
\text { scaffolding }\end{array}$ & $\begin{array}{l}\text { Teacher supports individual students and groups in resolving their doubts and encourages participation (e.g. "Use your } \\
\text { university email to log in.") }\end{array}$ \\
\hline & $\begin{array}{l}\text { Revise course } \\
\text { (learning) } \\
\text { design }\end{array}$ & Teacher uses timing and flow controls of the dashboard, to revise the script. \\
\hline & Wait and see & $\begin{array}{l}\text { Teachers delay their reaction to dashboard warnings and take actions using timing and flow controls (e.g. opening and } \\
\text { closing the open controls panel without using controls). }\end{array}$ \\
\hline & Check impact & Teachers revisit group messages to check whether students replied to the messages posted by the teachers. \\
\hline
\end{tabular}

aAll seven codes were used to code teachers' actions in the experimental condition. For the control condition, three codes were used: explain pattern; whole-class scaffolding; and targeted scaffolding. 
TABLE IV

TEACHERS' USE OF DASHBOARD CONTROLS

\begin{tabular}{|c|c|c|c|c|c|c|c|}
\hline Teacher & $\begin{array}{l}\text { Session } \\
\text { ID }\end{array}$ & $\begin{array}{l}\text { No. of voting warnings } \\
\text { received \& No. of } \\
\text { voting warnings } \\
\text { reacted }\end{array}$ & $\begin{array}{l}\text { No. of discussion } \\
\text { warnings received \& } \\
\text { No. of discussion } \\
\text { warnings reacted }\end{array}$ & $\begin{array}{l}\text { Total no. of chat messages posted } \\
\text { by teacher in continuing } \\
\text { discussion with groups }\end{array}$ & $\begin{array}{l}\text { Replies } \\
\text { received } \\
\text { from } \\
\text { students } \\
(\mathrm{Yes} / \mathrm{No})^{\mathrm{a}}\end{array}$ & $\begin{array}{l}\text { Flow } \\
\text { controls } \\
\text { used }^{\mathrm{a}, \mathrm{b}}\end{array}$ & $\begin{array}{l}\text { Timing } \\
\text { controls } \\
\text { used }^{\text {a }}\end{array}$ \\
\hline \multirow[t]{6}{*}{$\mathrm{T} 1$} & E11 & $1(1)$ & $2(2)$ & 2 & $\mathrm{Y}$ & $\mathrm{N}$ & $\mathrm{N}$ \\
\hline & E12 & $6(2)$ & $0(0)$ & $\mathrm{n} / \mathrm{a}$ & $\mathrm{n} / \mathrm{a}$ & $\mathrm{Y}$ (end) & $\mathrm{N}$ \\
\hline & E13 & $9(4)$ & $1(0)$ & $\mathrm{n} / \mathrm{a}$ & $\mathrm{n} / \mathrm{a}$ & Y (end) & $\mathrm{N}$ \\
\hline & E14 & $7(4)$ & $2(1)$ & 1 & $\mathrm{Y}$ & $\mathrm{Y}$ (end) & $\mathrm{N}$ \\
\hline & E15 & $0(0)$ & $0(0)$ & $\mathrm{n} / \mathrm{a}$ & $\mathrm{n} / \mathrm{a}$ & $\mathrm{Y}$ (end) & $\mathrm{N}$ \\
\hline & E16 & $0(0)$ & $1(1)$ & 14 & $\mathrm{Y}$ & Y (end) & $\mathrm{N}$ \\
\hline \multirow[t]{6}{*}{$\mathrm{T} 2$} & E21 & $0(0)$ & $0(0)$ & $\mathrm{n} / \mathrm{a}$ & $\mathrm{n} / \mathrm{a}$ & $\mathrm{N}$ & $\mathrm{N}$ \\
\hline & E22 & $0(0)$ & $1(0)$ & $\mathrm{n} / \mathrm{a}$ & $\mathrm{n} / \mathrm{a}$ & Y (end) & $\mathrm{N}$ \\
\hline & E23 & $0(0)$ & $2(0)$ & $\mathrm{n} / \mathrm{a}$ & $\mathrm{n} / \mathrm{a}$ & $\mathrm{N}$ & $\mathrm{N}$ \\
\hline & E24 & $0(0)$ & $0(0)$ & $\mathrm{n} / \mathrm{a}$ & $\mathrm{n} / \mathrm{a}$ & $\mathrm{Y}$ (end) & $\mathrm{N}$ \\
\hline & E25 & $0(0)$ & $0(0)$ & $\mathrm{n} / \mathrm{a}$ & $\mathrm{n} / \mathrm{a}$ & $\mathrm{Y}$ (end) & $\mathrm{Y}$ \\
\hline & E26 & $1(1)$ & $0(0)$ & $\mathrm{n} / \mathrm{a}$ & $\mathrm{n} / \mathrm{a}$ & $\mathrm{Y}$ (end) & $\mathrm{N}$ \\
\hline \multirow[t]{2}{*}{ T3 } & E31 & $2(2)$ & $2(1)$ & 1 & $\mathrm{Y}$ & $\mathrm{N}$ & $\mathrm{N}$ \\
\hline & E32 & $0(0)$ & $0(0)$ & $\mathrm{n} / \mathrm{a}$ & $\mathrm{n} / \mathrm{a}$ & Y (end) & $\mathrm{N}$ \\
\hline \multirow[t]{2}{*}{$\mathrm{T} 4$} & E41 & $0(0)$ & $0(0)$ & $\mathrm{n} / \mathrm{a}$ & $\mathrm{n} / \mathrm{a}$ & $\mathrm{Y}(\mathrm{end})$ & $\mathrm{Y}$ \\
\hline & E42 & $0(0)$ & $2(1)$ & 1 & $\mathrm{~N}$ & Y (end) & $\mathrm{N}$ \\
\hline
\end{tabular}

aY refers to Yes and N refers to No.

bOnly end flow control was used by the teachers. Pause and resume controls were not used.

two teachers in 2 of the 16 experimental sessions (E25 and E41) to reduce the time allocated to the voting and answer submission phases, respectively, allowing students to move to the next level of the script without waiting till the original design time expires.

In the control condition (without a dashboard), teachers explained patterns an average of 0.83 times per session $(\mathrm{SD}=$ 0.93). Further, whole-class scaffolding and targeted scaffolding were conducted an average of 2.33 times $(\mathrm{SD}=1.82)$ and 2.58 times per session $(\mathrm{SD}=1.38)$, respectively.

\section{B. Do Teachers' Orchestration Actions Affect Students' Participation in Activities?}

To address the second research question of the study, we examined how teachers' orchestration actions affect students' activity participation. Log data collected from the PyramidApp was used to calculate the percentage of students who participated in the voting and discussion out of the total number of students who started the activity. Then, the overall percentage of participation was calculated by summing up the percentages of voting participation and discussion participation and dividing by two (see Fig. 6).

In the experimental condition, students had a higher overall activity participation $(\mathrm{M}=72.05, \mathrm{SD}=14.75)$ compared to the control condition $(\mathrm{M}=64.66, \mathrm{SD}=12.62)$ but the difference was not significant; $\mathrm{t}(25)=1.400, \mathrm{p}=0.174$. Students' discussion participation was higher in the experimental condition $(\mathrm{M}=53.21, \mathrm{SD}=29.78)$ compared to the control condition $(M=41.81, S D=21.82)$ but the difference was not significant; $\mathrm{t}(25)=1.146, \mathrm{p}=0.263$. The voting participation was high (more than 87\%) in both the experimental condition $(\mathrm{M}=90.52, \mathrm{SD}=7.74)$ and control condition $(\mathrm{M}=87.52, \mathrm{SD}$ $=8.07)$ with no significant difference between the two conditions, $\mathrm{t}(25)=0.976, \mathrm{p}=0.339$.

The $\log$ data indicated that the percentage of individual answer submissions was higher in the experimental condition $(87 \%)$ than in the control condition (83\%). Students' postactivity questionnaire responses (see Section V.B for the questions) indicated that there were no significant differences with respect to their perceived learning (Q1) and satisfaction (Q2) in both the control (Q1: $\mathrm{M}=2.2, \mathrm{SD}=0.945 ; \mathrm{Q} 2: \mathrm{M}=$ $2.25, \mathrm{SD}=0.885)$ and experimental conditions $(\mathrm{Q} 1: \mathrm{M}=2.3$, $\mathrm{SD}=1.002 ; \mathrm{Q} 2: \mathrm{M}=2.22, \mathrm{SD}=0.9444$ ).

To understand the relation between teachers' actions (see Table III) and students' participation we conducted Spearman's correlation tests in both conditions (data was not normally

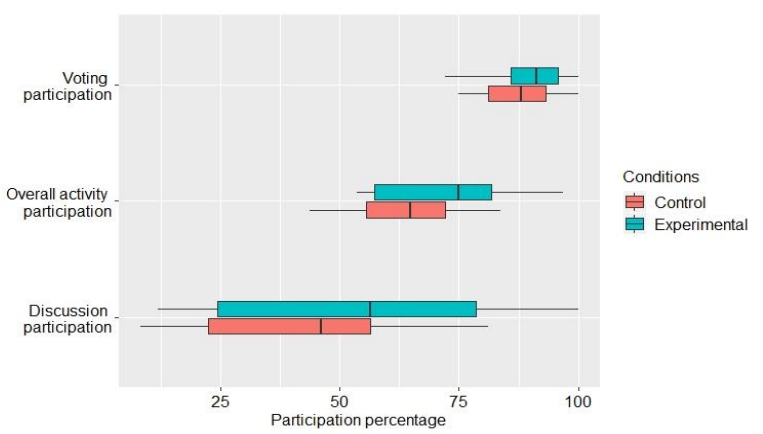

Fig. 6. Differences in students' discussion, overall and voting participation in control and experimental conditions. 
distributed). In the experimental condition, significant correlations were found between the teachers' targeted scaffolding and students' discussion participation $\left(\mathrm{r}_{\mathrm{s}}=0.673, \mathrm{p}\right.$ $=0.004)$ and teachers' targeted scaffolding and overall activity participation $\left(\mathrm{r}_{\mathrm{s}}=0.646, \mathrm{p}=0.007\right)$. In the control condition, there were no significant correlations between teachers' targeted scaffolding and students' discussion participation $\left(\mathrm{r}_{\mathrm{s}}=\right.$ $0.055, \mathrm{p}=0.865)$ or students' overall participation $\left(\mathrm{r}_{\mathrm{s}}=0.009\right.$, $\mathrm{p}=0.977)$. These results suggest that in the experimental condition when teachers' interventions were increasing at individual and group level, students' discussion and overall activity participation also increased or vice versa. Moreover, significant negative correlations were found between teachers' read data action and students' voting participation $\left(\mathrm{r}_{\mathrm{s}}=-0.523\right.$, $\mathrm{p}=0.038$ ) and between teachers' actions to whole class scaffolding and voting participation $\left(\mathrm{r}_{\mathrm{s}}=-0.517, \mathrm{p}=0.040\right)$. These results suggest that when students' voting participation was decreasing, teachers were reading more often the dashboard data and provided more support at the class level, or the reverse relation between teachers and students' actions occurred.

\section{DISCUSSION}

\section{A. How Did Teachers Use the Dashboard to Orchestrate Collaboration?}

Based on the results, in the experimental condition, the sensemaking action of reading data was observed more frequently than explaining patterns. In the post-activity questionnaire, teachers reported that the information presented in the dashboard helped them to: 1) gain awareness of activity participation (e.g. "All the information presented in the dashboard were useful to understand students' responses and participation"); 2) to be aware of the script progression (e.g. "I liked the time indicator and the red and blue visualisation because I knew when the students will proceed to the next level"); and 3) to combine dashboard information with their classroom observations (e.g. "I could combine what I was directly observing in the classroom with the information in the dashboard.") We interpret the findings as indicating that the information presented in the dashboard became useful and that the teachers sometimes used this information (reading data) to confirm their own understanding of (rather than explicitly mentioning) students' participation in the activity and progression through the script. This aligns with similar research that was conducted previously [30].

However, when compared to the experimental condition, in the control condition, explaining patterns were very low, indicating that access to the LA dashboard allowed teachers to gain awareness of collaboration.

In terms of pedagogical responses, in the experimental condition, both whole-class scaffolding and targeted scaffolding were observed less often in the control condition. This seemed to indicate that introducing an LA dashboard did not take teachers' attention away from the classroom, but helped teachers to provide more scaffolds at the class, group and individual levels, which influenced their teaching practices.
The presence of the wait-and-see posture in the experimental condition (e.g. teachers did not react immediately to the warnings associated with low-group participation, opening the control panel, and closing it without taking actions) can be explained by taking into account the teacher's responses to the post-activity questionnaire. Two teachers pointed out that participation warnings indicated the requirements for intervention - "Seeing the percentage of voting participation or the warnings was very useful," "Knowing that students did not chat, I will try to find ways for more interactions in a subsequent activity," "Entering in the chat was useful and enabled me to see the information in the chat (previous discussion, etc.)"-but the limited time allocated to the activity made it difficult to understand the influence of the intervention: "due to [the] fast grouping levels that occur in the classroom, it is hard to see how my prompts influence the students." Based on this, we believe that simultaneously receiving a number of warnings within the short activity duration in the dashboard may have created a situation in which some teachers could not decide which group(s) to attend to and faced difficulty in accessing the effects of feedback, which resulted in a wait-and-see posture. As pointed out in [31], there is a trade-off regarding the immediateness of teachers' actions, as actions taken too quickly based on warnings that take into account only partial representations of the students participation may not provide enough time for students to handle problems. Finding the right balance between when to generate warnings and when to provide immediate or delayed feedback may depend on a number of factors, including context and task type. This notion requires further research.

Regarding the teachers' use of dashboard controls, as indicated in Table IV, teachers did not often use flow and timing controls to revise the learning designs. In the post-activity questionnaire, teachers elaborated upon several reasons for this behaviour. First, it was not necessary to revise the designs of some activities, as the activities were planned quite conservatively: "I did not intensively use the controls, but I saw them as very useful. Changing times was not needed as my designs worked well in most sessions, but I needed to end Pyramid before [the time that was] planned in some sessions as [we] were running out of time and [I] thought that for slow Pyramids it was sufficient with two levels (although three levels were initially planned)." Second, teachers mentioned that they were reluctant to revise certain learning design parameters at run time, in particular time, and that they required further training or guidance regarding when to use such controls: "I didn't use a lot of timing controls because they will influence the whole activity and I was not sure if I can experiment [with] this in the class." Finally, teachers noted improvements that could be made regarding the placement of controls: "The controls were hidden and its presentation gave a feeling of complexity."

Although the teachers did not use the pause and resume controls in any of the experimental sessions, two teachers mentioned that those controls could be useful for orchestration: "In any case, I find it useful to be able to pause the class." The end flow control was extensively used by all four teachers 
(12|16 sessions) to stop activities before the time as planned in the original design. This indicates that having access to such controls is often useful when facing time constraints in the classroom.

Moreover, screen-captured data and observation notes indicated that the teachers that had not reacted to the voting or discussion warnings were due to one of the following reasons: 1) they were observing information in the Submission Related Information tab and missed the warnings that appeared in the process Related Information tab; 2) they were communicating with students and were not focusing on the dashboard; and 3) teachers already decided to end the activity before the planned duration and were summarizing the winning answers to the class and disregarded the warnings that appeared.

The teachers also pointed out that the user interface of the dashboard required improvements, especially if it were to be used on a more regular basis. For instance, the visualisations of groups' activity participation needs to be refined: "With the tables it was hard to compare groups; thus, a visualisation will clearly show which group participate more or less." Teachers also pointed out that having access to checkpoint analytics [32] would help them to detect and directly support late starters: "I'd have appreciated info about how many students were entering the activities in the beginning of the Pyramid so that I [could] go and check the problems of slow students." Further, two teachers emphasised that the terminology in the user interface should be changed: "The wording is clear and has all the information but perhaps [it] can be closer to the vocabulary of teachers." Regarding the timing controls, the teachers pointed out that "in the slider, the number could clarify if it refers to seconds [or] minutes." The teachers also suggested requirements for a new control that would allow them to skip intermediate levels of the Pyramid script when necessary. During the activities, we observed that the teachers faced typing difficulties when they tried to post messages to groups. In the next iteration, to alleviate this issue, we will provide pre-written messages that can be directly posted to groups.

The unique constraints of the learning sessions, imperfections regarding the usability of the LA dashboard, and the novelty of using analytics [27] may explain why few controls were used by the teachers in some sessions. The teachers' use of the dashboard controls may have also been influenced by factors such as teacher's satisfaction, years of teaching experience, agency, beliefs, skills, trust, cognitive load as well as technological, pedagogical, and content knowledge $[27,33]$ which requires further examination.

\section{B. Do Teachers' Orchestration Actions Affect Students' Participation in Activities?}

In order to better understand whether the improved overall collaboration was achieved as a result of improved conditions for collaboration (through teachers' pedagogical actions), we explored qualitative aspects of the collaboration. As indicated in [34], successful classroom collaboration is attained through the achievement of certain conditions: common goal, positive interdependence, coordination and communication, individual accountability, awareness, and joint rewards. In Table V, we present our interpretations of how each of the conditions was better facilitated in the experimental condition, in which the teacher had more control over the activity and hence could influence and increase students' participation in the activity.

\section{LIMITATIONS OF THE STUDY}

A limitation of the study is that the proposed dashboard was designed and evaluated in collaborative learning sessions that were scripted according to the Pyramid CLFP. Even if we believe that the pedagogical value, implementation complexity, and applicability to multiple contexts and subjects of the Pyramid CLFP makes it an interesting research focus, generalising the findings of the study to other structures for learning activities is difficult and requires further research. Creating a common framework that would enable comparison of empirical findings across studies with related research would help the field to form a broad body of research knowledge. In addition, more studies should evaluate whether the proposed technology could be part of teachers' common practice for orchestrating collaboration, as the teachers in this study expressed that they are interested in using the dashboard in future activities.

Another limitation is that teachers' behaviours during the sessions could have been captured using classroom recording, and the elements to which they paid attention could have been detected using eye-tracking technologies for fine-grained analysis. The present study did not measure whether the generated warnings and information visualisations of the dashboard added to teacher' orchestration load.

Finally, regarding the students aspects, given the limited time available in the classrooms we were unable to collect detailed

TABLE V

CONDITIONS OF FRUITFUL COLLABORATION

\begin{tabular}{|c|c|c|}
\hline Condition & $\begin{array}{l}\text { Control condition (no } \\
\text { dashboard for } \\
\text { teachers, only } \\
\text { PyramidApp) }\end{array}$ & $\begin{array}{l}\text { Experimental condition } \\
\text { (dashboard for teachers) }\end{array}$ \\
\hline Common goal & $\begin{array}{l}\text { Need to collectively } \\
\text { reach a consensus on a } \\
\text { common task. }\end{array}$ & $\begin{array}{l}\text { Students were more } \\
\text { responsible and focused as } \\
\text { teachers monitored activity. }\end{array}$ \\
\hline $\begin{array}{l}\text { Positive } \\
\text { Interdependence }\end{array}$ & $\begin{array}{l}\text { Participants are aware } \\
\text { that they need each } \\
\text { other to succeed. }\end{array}$ & $\begin{array}{l}\text { Students were more } \\
\text { responsible and focused as } \\
\text { teachers monitored activity. }\end{array}$ \\
\hline Coordination & $\begin{array}{l}\text { Flow aligned with the } \\
\text { pedagogical method or } \\
\text { intent. }\end{array}$ & $\begin{array}{l}\text { Teachers used the } \\
\text { dashboard controls to } \\
\text { further regulate the activity. }\end{array}$ \\
\hline Communication & $\begin{array}{l}\text { Intensity of } \\
\text { discussions. }\end{array}$ & $\begin{array}{l}\text { The number of messages } \\
\text { posted in the discussion } \\
\text { was high, but not } \\
\text { significantly high. }\end{array}$ \\
\hline $\begin{array}{l}\text { Individual } \\
\text { accountability }\end{array}$ & $\begin{array}{l}\text { Each student should } \\
\text { contribute. }\end{array}$ & $\begin{array}{l}\text { Students posted more } \\
\text { answers and contributed } \\
\text { more to voting and } \\
\text { discussions. }\end{array}$ \\
\hline $\begin{array}{l}\text { Awareness of } \\
\text { peers' work }\end{array}$ & $\begin{array}{l}\text { Students see answers } \\
\text { submitted by others. }\end{array}$ & $\begin{array}{l}\text { As a result of increased } \\
\text { answer submissions and } \\
\text { voting on peers' answers, } \\
\text { students took into account } \\
\text { the answers submitted by } \\
\text { peers. }\end{array}$ \\
\hline Joint rewards & $\begin{array}{l}\text { Groups that reach } \\
\text { agreement faster will } \\
\text { produce a winning } \\
\text { answer. }\end{array}$ & $\begin{array}{l}\text { Teachers revealed the } \\
\text { winning answers to the } \\
\text { class at the end of the } \\
\text { sessions. }\end{array}$ \\
\hline
\end{tabular}


qualitative responses or to conduct interviews to capture further information regarding perceived learning and satisfaction.

\section{CONCLUSIONS AND Future WORK.}

This study reported our practical experience related to designing a teacher-facing dashboard that aimed at supporting teachers in orchestrating scripted classroom collaboration. The findings of the study revealed how teachers made information on the dashboard actionable (not only based on automatic detection of low-participating groups but also because of how teachers used the information presented on the dashboard to inform their pedagogical actions, e.g. whole-class scaffolding, targeted scaffolding) and how teachers actions induced positive change in students' activity participation. In the following, we outline design principles for actionable dashboards to support CLFPs derived from the research:1) Warn teachers of critical events concerned with the epistemic facet related to the learning task but also to the social facet affecting the collaborative learning flow mechanisms: Enabling the flexible modification of learning scenarios in run-time is a necessary feature of orchestration technology. However, it is not sufficient if the technology is not helping teachers to take informed actions. In our study, teachers mentioned that they missed chances of reacting to critical events during collaboration as they are concerned about the epistemic and social facets of the learning activity in real-time. By generating automatic warnings to inform critical events, teachers can act instantly providing just in time support for students taking advantage of the orchestrable technology; 2) Offer capabilities to customize warnings: Criteria to generate warnings may depend on the type of task and teacher's expectations. Teachers wanted to have access to authoring features that allow them to modify criteria for generating warnings; 3) Generate action-impact indicators: Teachers mentioned that they want to know how their interventions or pedagogical actions impacted students. For instance, teachers wanted to know whether posting a message to a group resulted in increased students' discussion participation; 4) Align students' artefacts with teacher's expectations: Teachers want to rapidly evaluate if the answers produced by the students are aligned with their expectations. This was challenging as pyramid CLFP tasks can be of different natures and the tasks used in our study were open-ended. Providing space for teachers to input keywords they would like to see in students' answers and matching of teacher's expected answers versus students' answers can facilitate a first approach for real-time content evaluation; 5) Avoid hidden menus: Teachers indicated that the dashboard controls placed in a hidden menu resulted in added complexity and usability issues. They wanted all information and controls of the dashboard to be visible and easily accessible; 6) Use teacher's vocabulary instead of technical terms: Teachers asked to use language close to teacher's vocabulary as technical terms used in the dashboard are difficult to interpret in real-time.; 7) Provide automatic action recommendations: Teachers mentioned that having access to dashboard controls (e.g. pause, resume, etc.) is useful. However, as shown in the study results the use of such controls in the run time of the activity is less, which indicates that there is a gap between teachers' subjective perception of such controls and their real-time use. This may occur due to the teacher's lack of familiarity with the technology, lack of confidence in revising the learning design in real-time, or due to lack of focus towards the use of controls as they are busy in evaluating epistemic and social aspects of the learning scenario. Generating automatic action recommendations of when to use dashboard controls and giving them the flexibility to accept or reject the recommendations would facilitate to bridge the gap between perception and technological affordances.

Future studies around teacher orchestration may benefit from considering the use of novel tracking technologies. For example, studies related to electrodermal activity (EDA) and its application for detecting changes in the level of arousal [35], especially within the learning context [36], suggest that this method can be used to monitor the state of teachers at the time they carry out actions when using the dashboard. Studies of cognitive load when teaching over the video, show that physiological measurements, such as arousal measured by galvanic skin response, correspond to the self-reported states of cognitive load [37]. In our future research, we will equip teachers with an Shimmer3 GSR+ device, which is suitable for measuring EDA with minimal disturbance to the teachers' usual patterns of behavior. Even though these kinds of measurements require devices to be attached to the teacher, they can provide useful data, especially for tracking the causality of teachers' actions. Another way to understand teachers' behaviour during orchestration is to track sound levels in the classroom [38]. An off-the-shelf sound meter could be carried by teachers to detect the level of sound that reaches them. This information could explain certain teachers' actions, like sudden interruptions of the activity or pauses for intervention. By combining EDA and sound measurements as well as tracking the actions carried out while using the dashboard, we could employ a multimodal system that provides various types of complementary data and focuses on teachers' behaviour. For instance, data collected from such devices together with self-reported measurements could provide information regarding perceived cognitive load of the teachers when using dashboards for orchestration purposes. Eye tracking can help indicate a correlation between more frequent looking at students when the cognitive load is increased [33]. More research on eye tracking technology implies that, combined with video recordings, this physiological measurement can be a good addition to qualitative measures in assessing cognitive load [33]. Note, however, that while this type of multimodal learning analytics is interesting for research purposes, there are ethical implications in its applicability to real scenarios [39].

Regarding student aspects, tracking technologies can be used to determine the positions of group participants, which can inform how the positioning affects overall group performance [40]. By comparing this information to groups' performance and actions during an activity, suggestions regarding orchestration can be provided for the teacher. Similarly, EDA approaches with students can be investigated. EDA measurements in students are present in studies where the possibility of reducing stress is analyzed with the aim to obtain 
better learning outcomes [41]. A Multimodal system consisting of EDA, heart rate measurement device, finger-based GSR sensor and surveys, demonstrates that prediction algorithms can provide $88.8 \%$ of accuracy in predicting stress with college students [42]. By measuring voice activity (speaking time and location of the student) and relating it to the actions students take (discussion, time for voting, etc.), we can thoroughly analyse the frequency of face-to-face contact and its relevance to this approach [43]. Inertial measurement unit (IMU) sensors, such as the Shimmer3 IMU Unit, which are used for this kind of tracking, are non-invasive, and can be placed on each participant without disturbing them during the activity [44].

\section{REFERENCES}

[1] L. Kobbe, A. Weinberger, P. Dillenbourg, A. Harrer, R. Hämäläinen, P. Häkkinen, and F. Fischer, "Specifying computer-supported collaboration scripts," Int. J. Comput.-Supported Collaborative Learn., vol. 2, no. 2, pp. 211-224, Sep. 2007, doi: 10.1007/s11412-007-9014-4.

[2] C. Kaendler, M. Wiedmann, N. Rummel, and H. Spada, "Teacher competencies for the implementation of collaborative learning in the classroom: a framework and research review," Educational Psychol. Rev., vol. 27, no. 3, pp. 505-536, Sep. 2015, doi: 10.1007/s10648-014-9288-9.

[3] P. Dillenbourg and P. Tchounikine, "Flexibility in macro-scripts for computer-supported collaborative learning," J. Comput. Assisted Learn., vol. 23, no. 1, pp. 1-13, Jan. 2007, doi: 10.1111/j.13652729.2007.00191.x.

[4] D. Hernández-Leo, J. I. Asensio-Pérez, Y. Dimitriadis, and E. D. Villasclaras-Fernández, "Generating CSCL scripts: from a conceptual model of pattern languages to the design of real scripts," in Technol. Enhanced Learn., vol. 2, P. Goodyear and S. Retalis, Eds., Rotterdam, The Netherlands: Sense, 2010, pp. 49-64.

[5] I. Amarasinghe, D. Hernández-Leo, K. Manathunga, and A. Jonsson, "Sustaining continuous collaborative learning flows in MOOCs: orchestration agent approach," J. Universal Comput. Sci., vol. 24, no. 8, pp. 1034-1051, Aug. 2018, doi: 10.3217/jucs-024-08-1034.

[6] P. Dillenbourg, G. Zufferey, H. Alavi, P. Jermann, S. Do-Lenh, Q. Bonnard, S. Cuendet, and Frédéric Kaplan, "Classroom orchestration: the third circle of usability," in Proc. 9th Int. Conf. Comput.-Supported Collaborative Learn., Hong Kong, China, Jul. 2011, pp. 510-517.

[7] A. Cooper, "What is analytics? definition and essential characteristics," in JISC CETIS Analytics Ser., vol. 1, no. 5, 2012, Accessed: Sep. 20, 2020. [Online]. Available: http://publications.cetis.org.uk/2012/521

[8] R. Prestigiacomo, R. Hadgraft, J. Hunter, L. Locker, S. Knight, E. van den Hoven, and R, Martinez-Maldonado, "Learning-centred translucence: an approach to understand how teachers talk about classroom data," in Proc. 10th Int. Conf. Learn. Analytics Knowl., Mar. 2020, pp. 100-105, doi: $10.1145 / 3375462.3375475$.

[9] R. L. Jørnø and K. Gynther, "What constitutes an 'actionable insight' in learning analytics?,” J. Learn. Analytics, vol. 5, no. 3, pp. 198-221, Dec. 2018, doi: 10.18608/jla.2018.53.13.

[10] R. Martinez-Maldonado, A. Pardo, N. Mirriahi, K. Yacef, J. Kay, and A. Clayphan, "The LATUX workflow: designing and deploying awareness tools in technology-enabled learning settings," in Proc. $5^{\text {th }}$ Int. Conf. Learn. Analytics Knowl., New York, NY, USA, Mar. 2015, pp. 1-10, doi: $10.1145 / 2723576.2723583$.

[11] G. Siemens and D. Gašević, "Guest editorial - learning and knowledge analytics," Educational Technol. Soc., vol. 15, no. 3, pp. 1-2, Jul. 2012.

[12] A. L. Dyckhoff, V. Lukarov, A. Muslim, M. A. Chatti, and U. Schroeder, "Supporting action research with learning analytics," in Proc. $3 r d$ Int.
Conf. Learn. Analytics Knowl., Leuven, Belgium, Apr. 2013, pp. 220 229, doi: $10.1145 / 2460296.2460340$

[13] K. Verbert, E. Duval, J. Klerkx, S. Govaerts, and J. L. Santos, "Learning analytics dashboard applications," Amer. Behav. Scientist, vol. 57, no. 10 , pp. 1500-1509, Oct. 2013, doi: 10.1177/0002764213479363.

[14] H. S. Alavi and P. Dillenbourg, "An ambient awareness tool for supporting supervised collaborative problem solving," IEEE Trans. Learn. Technol., vol. 5, no. 3, pp. 264-274, Sep. 2012, doi: 10.1109/TLT.2012.7.

[15] E. Mercier, "Teacher orchestration and student learning during mathematics activities in a smart classroom," Int. J. Smart Technol. Learn., vol. 1, no.1, pp. 33-52, 2016, doi: 10.1504/IJSMARTTL.2016.078160.

[16] J. D. Slotta, M. Tissenbaum, and M. Lui, "Orchestrating of complex inquiry: three roles for learning analytics in a smart classroom infrastructure," in Proc. 3rd Int. Conf. Learn. Analytics Knowl., Leuven, Belgium, Apr. 2013, pp. 270-274, doi: 10.1145/2460296.2460352.

[17] B. B. Schwarz, N. Prusak, O. Swidan, A. Livny, K. Gal, and A. Segal, "Orchestrating the emergence of conceptual learning: a case study in a geometry class," Int. J. Comput.-Supported Collaborative Learn., vol. 13, no. 2, pp. 189-211, Jun. 2018, doi: 10.1007/s11412-018-9276-z.

[18] I. Jivet, M. Scheffel, M. Specht, and H. Drachsler, "License to evaluate: preparing learning analytics dashboards for educational practice," in Proc. 8th Int. Conf. Learn. Analytics Knowl., Sydney, NSW, Australia, Mar. 2018, pp. 31-40, doi: 10.1145/3170358.3170421.

[19] B. A. Schwendimann et al., "Perceiving learning at a glance: a systematic literature review of learning dashboard research," IEEE Trans. Learn. Technol., vol. 10, no. 1, pp. 30-41, Jan. 2017, doi: 10.1109/TLT.2016.2599522.

[20] R. Martinez-Maldonado, J. Kay, K. Yacef, M. T. Edbauer, and Y. Dimitriadis, "MTClassroom and MTDashboard: supporting analysis of teacher attention in an orchestrated multi-tabletop classroom," in Proc. 10th Int. Conf. Comput.-Supported Collaborative Learn., Madison, USA, Jun. 2013, pp. 119-128, doi: 10.22318/cscl2013.1.320.

[21] R. Martinez-Maldonado, A. Collins, J. Kay, and K. Yacef, "Who did what? Who said that? Collaid: an environment for capturing traces of collaborative learning at the tabletop," in Proc. ACM Int. Conf. Interactive Tabletops Surfaces, New York, NY, USA, Nov. 2011, pp. 172-181, doi: $10.1145 / 2076354.2076387$.

[22] I. G. Rojas, R. M. C. García, and D. Kloos, "Orchestration and feedback in lab sessions: improvements in quick feedback provision," in Proc. 6th Eur. Conf. Technol. Enhanced Learn., Palermo, Italy, Sep. 2011, pp. 424429, doi: 10.1007/978-3-642-23985-4_33.

[23] S. Do-Lenh, P. Jermann, A. Legge, G. Zufferey, and P. Dillenbourg, "TinkerLamp 2.0: designing and evaluating orchestration technologies for the classroom," in Proc. 7th Eur. Conf. Technol. Enhanced Learn., Saarbrücken, Germany, Sep. 2012, pp. 65-78, doi: 10.1007/978-3-64233263-0_6.

[24] A. van Leeuwen, "Learning analytics to support teachers during synchronous CSCL: balancing between overview and overload," J. Learn. Analytics, vol. 2, no. 2, pp. 138-162, Dec. 2015, doi: 10.18608/jla.2015.22.11

[25] W. Matcha, N. Ahmad Uzir, D. Gasevic, and A. Pardo, "A systematic review of empirical studies on learning analytics dashboards: a selfregulated learning perspective," IEEE Trans. Learn. Technol., vol. 13, no. 2, pp. 226-245, May. 2019, doi: 10.1109/TLT.2019.2916802.

[26] R. Bodily and K. Verbert, "Review of research on student-facing learning analytics dashboards and educational recommender systems," IEEE Trans. Learn. Technol., vol. 10, no. 4, pp. 405-418, Oct. 2017, doi: 10.1109/TLT.2017.2740172. 
[27] A. Wise and Y. Jung, "Teaching with analytics: towards a situated model of instructional decision-making," J. Learn. Analytics, vol. 6, no. 2, pp. 53-69, Jul. 2019, doi: 10.18608/jla.2019.62.4.

[28] K. Manathunga and D. Hernández-Leo, "Authoring and enactment of mobile pyramid-based collaborative learning activities," Brit. J. Educational Technol., vol. 49, no. 2, pp. 262-275, Oct. 2018, doi: 10.1111/bjet.12588.

[29] P. Wang, P. Tchounikine, and M. Quignard, "Chao: a framework for the development of orchestration technologies for technology-enhanced learning activities using tablets in classrooms," Int. J. Technol. Enhanced Learn., vol. 10, no. 1-2, pp. 1-21, 2018.

[30] I. Molenaar and C. K. Campen, "Teacher dashboards in practice: usage and impact," in Proc. 12th Eur. Conf. Technol. Enhanced Learn., Tallinn, Estonia, Sep. 2017, pp. 125-138, doi: 10.1007/978-3-319-66610-5_10.

[31] R. Martinez-Maldonado, "A handheld classroom dashboard: teachers' perspectives on the use of real-time collaborative learning analytics," Int. J. Comput.-Supported Collaborative Learn., vol. 14, no. 3, pp. 383-411, Sep. 2019, doi: 10.1007/s11412-019-09308-Z

[32] L. Lockyer, E. Heathcote, and S. Dawson, "Informing pedagogical action: aligning learning analytics with learning design," Amer. Behav. Scientist, vol. 57, no. 10, pp.1439-1459, Oct. 2013, doi: $10.1177 / 0002764213479367$.

[33] L. P. Prieto, K. Sharma, and P. Dillenbourg, "Studying teacher orchestration load in technology-enhanced classrooms," in Proc. 10th Eur. Conf. Technol. Enhanced Learn., Toledo, Spain, Sep. 2015, pp. 268 281, doi: 10.1007/978-3-319-24258-3_20.

[34] E. Szewkis, M. Nussbaum, T, Rosen, J. Abalos, F. Denardin, D. Caballero, A. Tagle, and C. Alcoholado, "Collaboration within large groups in the classroom," Int. J. Comput.-Supported Collaborative Learn., vol. 6, no. 4, pp. 561-575, Dec. 2011, doi: 10.1007/s11412-0119123-y.

[35] A. Greco, G. Valenza, L. Citi, and E. P. Scilingo, "Arousal and valence recognition of affective sounds based on electro dermal activity," IEEE Sensors J., vol. 17, no. 3, pp. 716-725, Feb. 2017, doi: 10.1109/JSEN.2016.2623677.

[36] H. J. Pijeira-Díaz, H. Drachsler, P. A. Kirschner, and S. Järvelä, "Profiling sympathetic arousal in a physics course: how active are students?," $J$. Comput. Assisted Learn., vol 34, no. 4, pp. 397-408, Aug. 2018, doi: 10.1111/jcal.12271.

[37] V. Hoogerheide, A. Renkl, L. Fiorella, F. Paas, and T. Van Gog, "Enhancing example-based learning: Teaching on video increases arousal and improves problem-solving performance," J. Educational Psychol., vol. 111, no. 1, pp. 45-56, 2019, doi: 10.1037/edu0000272.

[38] J. Kristiansen, R. Persson, S. P. Lund, H. Shibuya, and P. M. Nielsen, "Effects of classroom acoustics and self-reported noise exposure on teachers' well-being," Environ. Behav., vol. 45, no. 2, pp. 283-300, Feb. 2013, doi: 10.1177/0013916511429700.

[39] M. Beardsley, P. Santos, D. Hernández-Leo, and K. Michos, "Ethics in educational technology research: informing participants in data sharing risks," Brit. J. Educational Technol., vol. 50, no. 3, pp. 1019-1034, Mar. 2019, doi: 10.1111/bjet.12781.

[40] M. Vujovic, S. Tassani, and D. Hernández-Leo, "Motion capture as an instrument in multimodal collaborative learning analytics," in Proc. 14th Eur. Conf. Technol. Enhanced Learn., Delft, The Netherlands, Sep. 2019, pp. 761-764, doi: 10.1007/978-3-030-29736-7_49.

[41] A. Joshi, R. Kiran, and A. N. Sah, "An experimental analysis to monitor and manage stress among engineering students using galvanic skin response meter," Work, vol. 56, no. 3, pp. 409-420, Apr. 2017, doi: 10.3233/WOR-172507.

[42] I. Villanueva, M. Valladares, and W. Goodridge, "Use of galvanic skin responses, salivary biomarkers, and self-reports to assess undergraduatestudent performance during a laboratory exam activity," $J$. Visualized Experiments, vol. 108, no. e53255, pp. 79-91, 2016, doi: $10.3791 / 53255$

[43] N. Gligoric, A. Uzelac, S. Krco, I. Kovacevic, and A. Nikodijevic, "Smart classroom system for detecting level of interest a lecture creates in a classroom," J. Ambient Intell. Smart Environ., vol. 7, no. 2, pp. 271-284, Jan. 2015, doi: 10.3233/AIS-150303.

[44] Q. Yuan and I. Chen, "Localization and velocity tracking of human via 3 IMU sensors," Sensors Actuators A: Physical, vol. 212, pp. 25-33, Jun. 2014, doi:10.1016/j.sna.2014.03.004

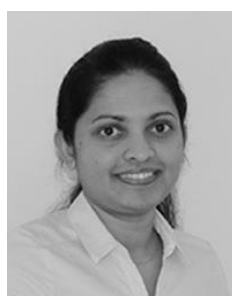

Ishari Amarasinghe received the M.Sc. degree in Intelligent Interactive Systems from the Universitat Pompeu Fabra (UPF), Barcelona, in 2016. She is currently working toward the Ph.D. degree in Information and Communication Technologies with the UPF. Her research interests include computer-supported collaborative learning and learning

analytics.

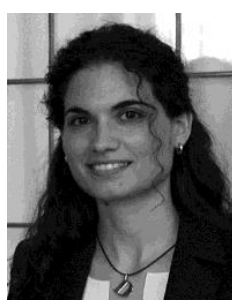

Davinia Hernández-Leo is Full Professor, ICREA Academia Fellow and head of the Interactive and Distributed Technologies Group (TIDE) at the ICT Department of Universitat Pompeu Fabra, Barcelona. She received the MS and $\mathrm{PhD}$ degrees in telecommunications engineering from the University of Valladolid, in 2003 and 2007, respectively. Her research interests focus on learning design technologies, CSCL, community platforms, data analytics, and interoperable architectures for learning.

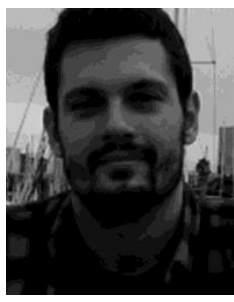

Konstantinos Michos received the M.Sc. degree in Educational Technology from the University of Saarland in Germany and his Ph.D. in Information and Communication Technologies from the Universtitat Pompeu Fabra in Spain. His research interests lie in the fields of Learning Design, Learning Analytics and Computer Supported Collaborative Learning..

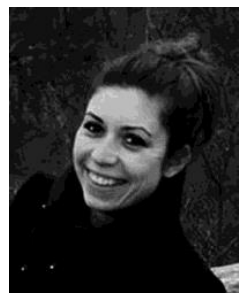

Milica Vujovic is a INPhINIT "la Caixa" Marie Curie Ph.D. candidate at the ICT Department of Universitat Pompeu Fabra, Barcelona. She is an architectural and mechanical engineer with a history of working in the academia, architecture, mechanical and industrial engineering industry. Also, she owns previous experience in teaching, within multidisciplinary subjects held at the Faculty of Architecture, University of Belgrade. She obtained a Master's Degree in Architecture (2011) and Master's Degree from Faculty of Mechanical Engineering (2014). Her research interests focus on Mechatronics, Human Computer Interaction and Smart Learning Environments. 